\title{
Case Report of a Septum Pellucidum Cavernoma Surgically Resected via Inferior Parietal Approach and Short Literature Review
}

\author{
Constantinos Picolas ${ }^{1 *}$, Konstantinos Faropoulos ${ }^{2}$, Kyriaki Kekempanou ${ }^{3}$, \\ Georgios Gatzounis ${ }^{2}$ \\ ${ }^{1}$ Panarcadian General Hospital, Neurosurgery Department, Terma Erythrou Stavrou, Tripoli, Greece \\ ${ }^{2}$ Patras University Hospital, Neurosurgery Department, Rio, Patras, Greece \\ ${ }^{3}$ Patras University Hospital, Pathology Department, Rio, Patras, Greece \\ Email: "cpicolas@upatras.gr
}

Received 13 February 2016; accepted 8 April 2016; published 11 April 2016

Copyright (C) 2016 by authors and Scientific Research Publishing Inc.

This work is licensed under the Creative Commons Attribution International License (CC BY).

http://creativecommons.org/licenses/by/4.0/

(c) (i) Open Access

\begin{abstract}
Background and Importance: Cavernomas of the septum pellucidum represent an extremely rare subtype of CNS cavernous angiomas which are a rare subtype of CNS tumors. Intraventricular cavernomas of the body of the lateral ventricle are usually treated by the transcallosal approach. Clinical Presentation: We present a case of a fifty-eight year old man with a septum pellucidum cavernoma successfully treated operatively by means of the inferior parietal transcortical transventricular approach. This unusual and scarcely documented tumor was situated at the posterior third of the septum pellucidum. The patient had a good recovery with no focal deficit. Conclusion: Septum pellucidum cavernomas are extremely rare lesions. Inferior parietal transcortical approach is a safe alternative to the commonly used transcallosal approach for lesions of the posterior half of the septum pellucidum.
\end{abstract}

\section{Keywords}

Septal Cavernoma, Septum Pellucidum, Transcallosal Approach, Inferior Parietal Transcortical

\section{Introduction}

Cavernous angiomas or cavernomas are relatively unusual hamartomatous vascular malformations of the central "Corresponding author.

How to cite this paper: Picolas, C., Faropoulos, K., Kekempanou, K. and Gatzounis, G. (2016) Case Report of a Septum Pellucidum Cavernoma Surgically Resected via Inferior Parietal Approach and Short Literature Review. Open Journal of Modern Neurosurgery, 6, 68-75. http://dx.doi.org/10.4236/ojmn.2016.62013 
nervous system (CNS). While the prevalence among CNS vascular malformations is $5 \%$ - $13 \%$, the overall prevalence in the general population is $0.02 \%-0.13 \%$ [1]. Histopathologically, they consist of an enlarged, lobulated, leaned vascular wall, surrounded by a monolayer of endothelial cells and collagen fibers. Characteristically no cerebral tissue is found inside the matrix of the aberrant endothelium. Given that they contain thrombi of multiple stages of degradation, they radiologically resemble a mulberry.

Intraventricular cavernomas (IVC) are a rare subtype of cavernous malformations. Their prevalence is $2.5 \%$ $10.8 \%$ among all the intracranial cavernomas [2]-[4]. More specifically, cavernomas of the septum pellucidum constitute a rare subtype of intraventricular cavernomas. To our knowledge, at present only four septal cavernomas have been reported in the literature [5]-[8]. ${ }^{1}$

We present a case of a cavernoma located at the posterior third of the septum pellucidum and argue in favor of our choice of surgical approach which we consider a reasonably safe operative alternative to the transcallosal approach.

\section{Clinical Presentation}

A 58 year old male had a history of 5 days of persistent headache resistant to analgesics. Due to the addition of mild personality and memory changes to his clinical outlook he was admitted to the ER where a CT scan was performed following his physical examination. A lesion of the posterior third of the septum pellucidum was revealed with an additional intraventricular hemorrhage in the body and atrium of the right lateral ventricle (Figure 1). A subsequent MRI scan showed an oval $2 \times 1.5 \mathrm{~cm}$ tumor with mixed dispersed iso- and hyperintense nodular loci (Figure 2) in T1 sequence with no particular enhancement with gandolenium (Figure 3) and hypointense with dispersed nodular hyperintense loci in T2. Two days after admission the patient's conscious level deteriorated (GCS: 12/15). Urgent CT scan revealed acute hydrocephalus due to intraventricular haemorrhage (Figure 4) and an external ventriculostomy was performed.

The definite treatment consisted in the surgical removal of the intraventricular hemorrhage and the resection of the tumor via an inferior parietal transcortical transventricular approach (Figure 5). Pathology study showed that the lesion was composed of multiple hyalinised vascular channels of varying size and shape devoid of intervening neural parenchyma, features characteristic of cavernous angioma. Additional pathologic features included vascular congestion, thrombosis, focal calcification and acute inflammation (Figure 6(a) \& Figure 6(b)). Patient had a good immediate postoperative course and after the correction of occurrent postoperative electrolyte disturbances he was discharged 20 days after admission. At the time of discharge he had a mild personality and memory deficit, with a Karnofsky scale of 90 (Figure 7). Six months later, mild short memory disturbances persisted and he was referred to a psychiatrist.

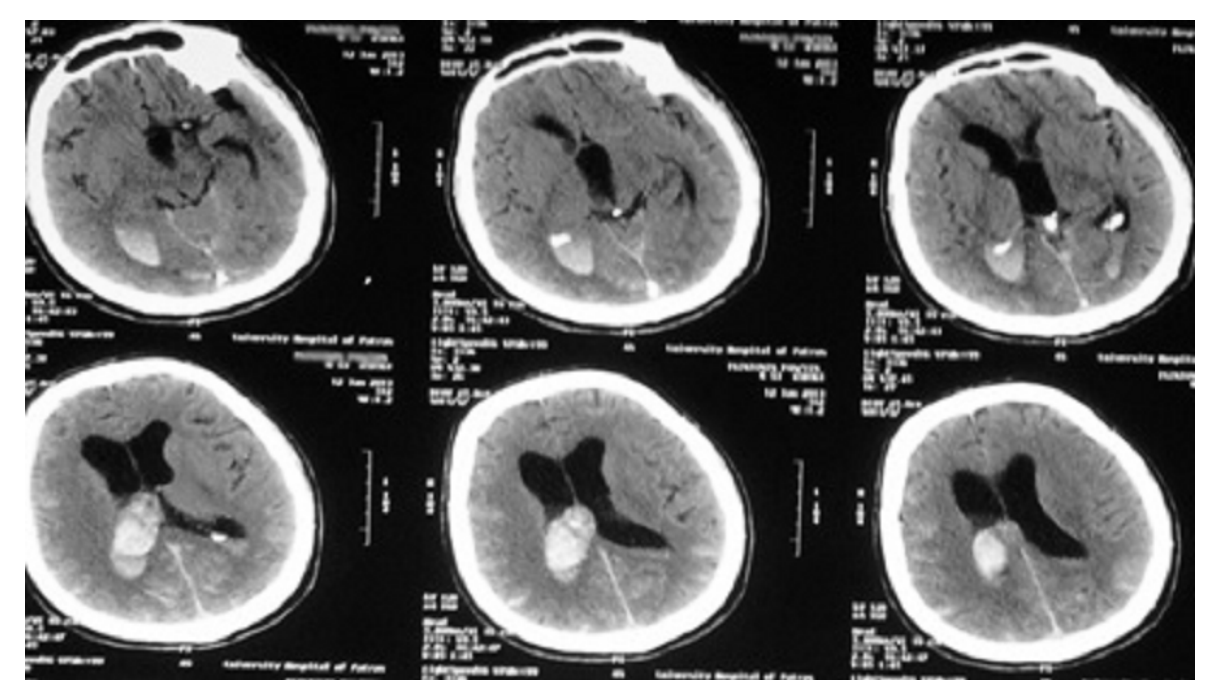

Figure 1. Computer tomography at presentation. Notice the hyperintense centrally located lesion with the perilesional intraventricular hemorrhage into the atrium and occipital horn.

${ }^{1}$ A PubMed search of the keyword "septum pellucidum cavernoma” returns only four relative articles. 


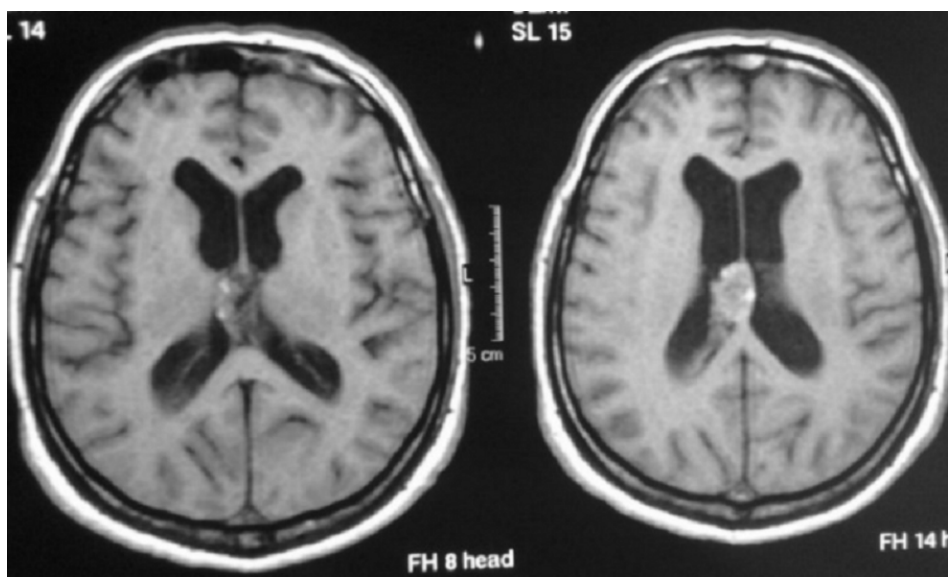

Figure 2. T1-no contrast. A posterior third septum pellucidum oval shaped lesion with iso- and hypersignal nodular loci.

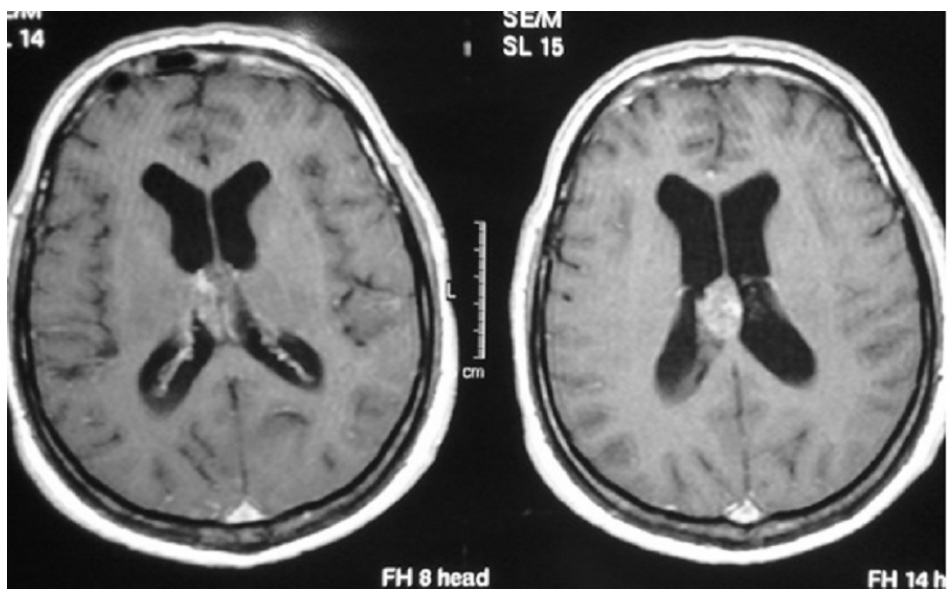

Figure 3. T1 + Gd. Mild nodular enhancement.

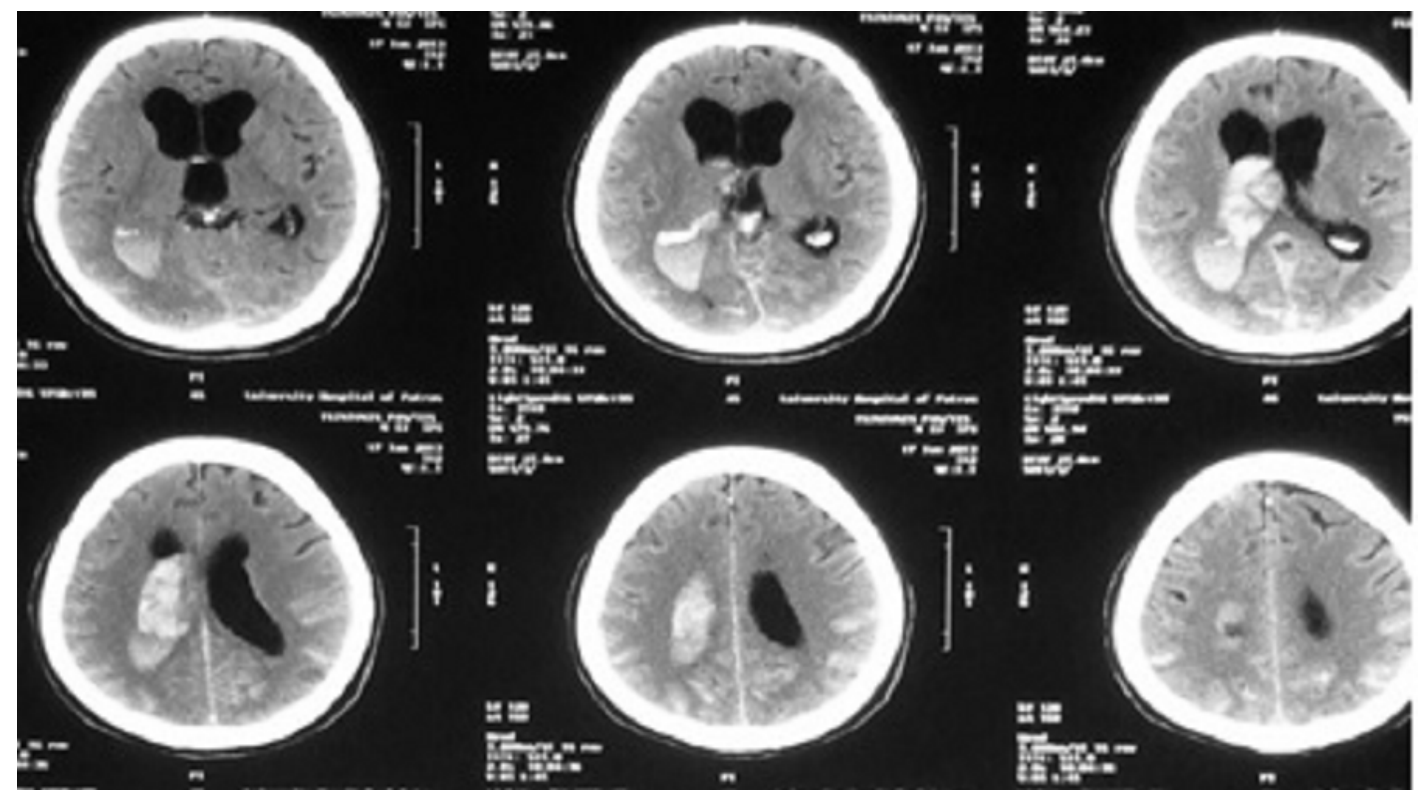

Figure 4. The ventricular system appears relatively dilated with recent intraventricular hemorrhage extending to the body and frontoparietal sulci. 


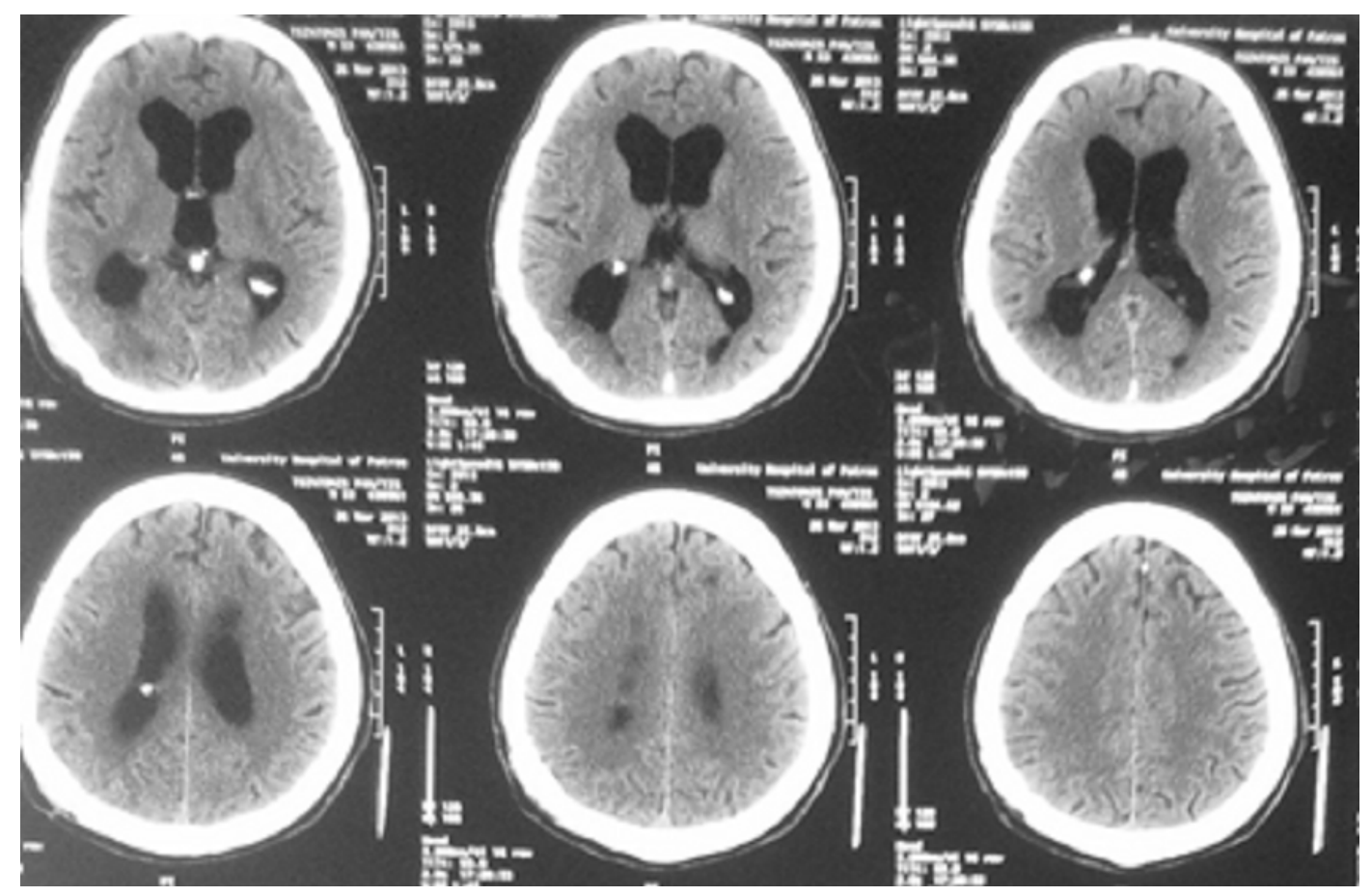

Figure 5. Post-operative computed tomography.

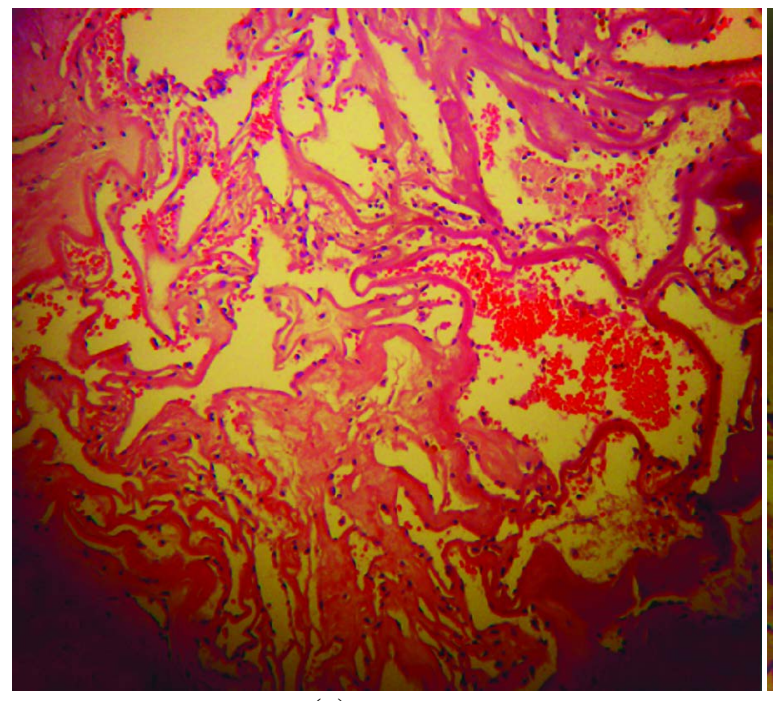

(a)

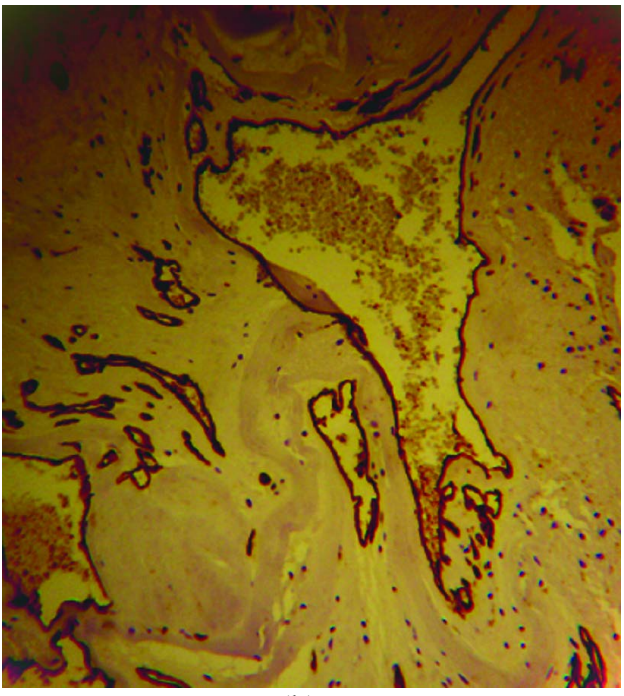

(b)

Figure 6. Histological photomicrographs at low magnification revealed a cluster of variably ectatic vascular spaces with prominent hyalinisation of their walls and without intervening neural elements (a) lined by CD31 positive flattened endothelium (b).

\section{Discussion}

As a short review of treatment options we should mention that the management of IVCs follows the same basic principles as with the rest of the CNS cavernomas. For example, IVCs cannot be treated with radiotherapy only. Although there are reports where intraparenchymal cavernomas were managed with stereotactic radiotherapy, those reports are mainly restricted to cases of inoperable cavernomas due to their location [9] [10]. Additionally, the use of radiotherapy as a standalone treatment of an IVC, contains the risk of rebleeding, proliferation and recurrence of the cavernoma [11]-[13]. Finally, a direct comparison of stereotactic radiotherapy with surgical 


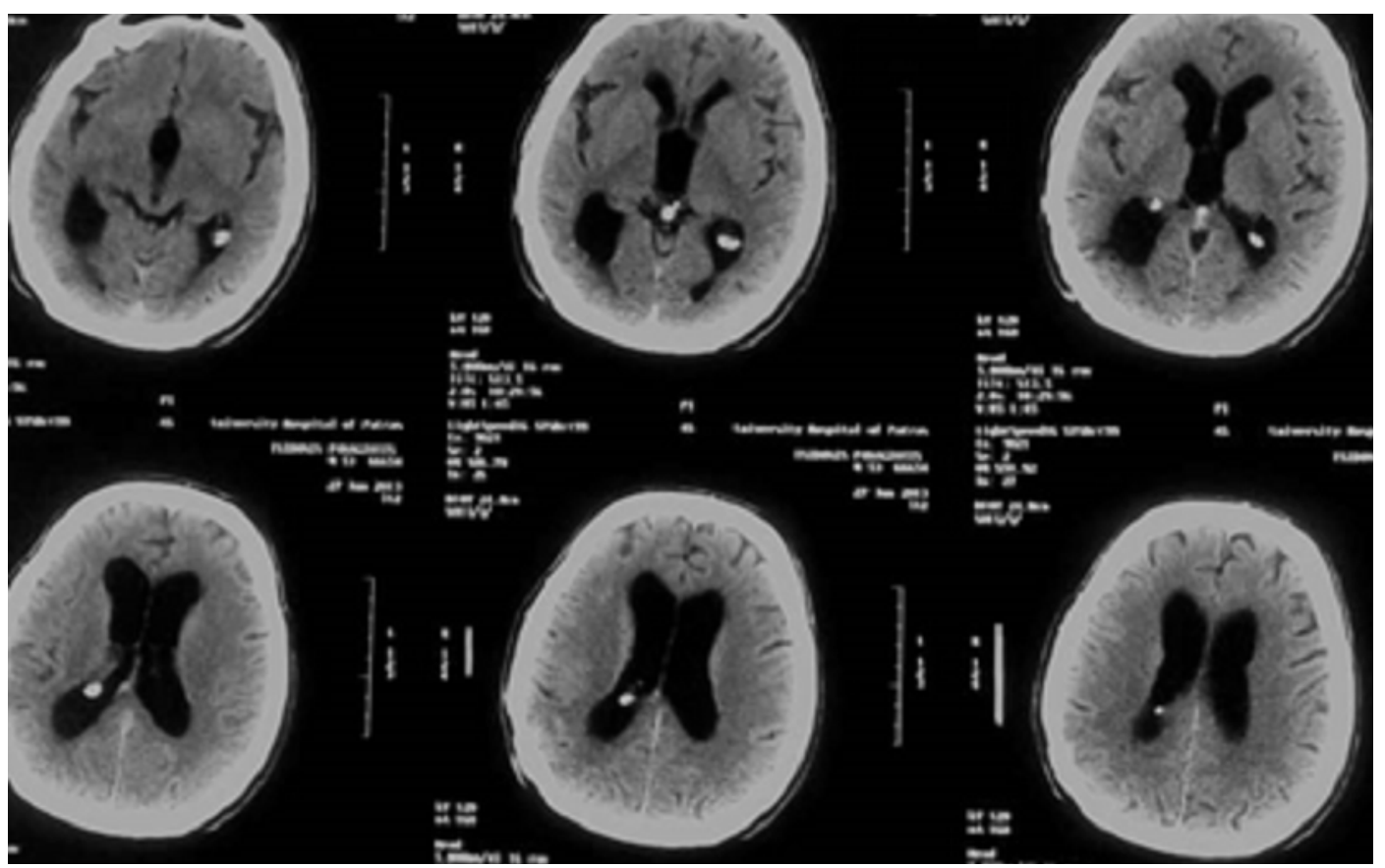

Figure 7. 6 months follow up computed tomography.

extraction of supratentorial cavernomas shows that the latter reduces the hazard of rebleeding and offers better control of the post-treatment epileptic seizures [14].

The benefits of endoscopic IVC resection are the smaller craniotomy and the better visualization of the anatomy around the mass [15]. At present, given the rarity of the entity, the international experience in endoscopic resecting of IVCs is limited. Although there are some reports of successful endoscopic removal [16] [17], we are still far from considering this technique as a common alternative option.

a) Surgical Treatment

The recommended approaches for reaching the septal region are of the transcortical and transcallosal variety. These are the widely accepted approaches for the frontal horn and the body of the lateral ventricles. They are:

- The anterior and posterior interhemispheric transcallosal.

- The frontal and parietal transcortical transventricular.

Transcallosal approaches offer better visualization and access for bilateral tumor manipulation. The potential complications of these approaches include the possibility of a rolandic vein complex and superior sagittal sinus injury, pericallosal artery injury and the disconnection neurological syndrome. Damage to the fornices or internal cerebral veins are common complications of both the transcallosal and transcortical approaches.

Transcortical approaches although considered by some safer from a complications point of view, injury to eloquent cortex and postoperative seizures notwithstanding [18], offer less opportunities for accessible tumor manipulation as the contralateral site is initially out of view. Additionally the presence of hydrocephalus is a relative prerequisite to minimize the depth of dissection of the intervening parenchyma.

b) The inferior parietal transcortical transventricular approach

In our opinion the inferior parietal transcortical transventricular approach, usually recommended for lesions of the atrium of the lateral ventricle, may be extended in use to include surgical pathology of the posterior body of the lateral ventricles. We successfully used this approach in this particular case.

More specifically we were faced with the following empirical data:

1) A lesion located at the posterior third of the septum pellucidum (Figure 8),

2) The tumor tilted mostly to the right (Figure 2, Figure 3),

3) With hemorrhage into the trigone (Figure 4).

The available operative options for this case could be:

1) A posterior interhemispheric transcallosal approach,

2) A superior parietal transcortical approach, 


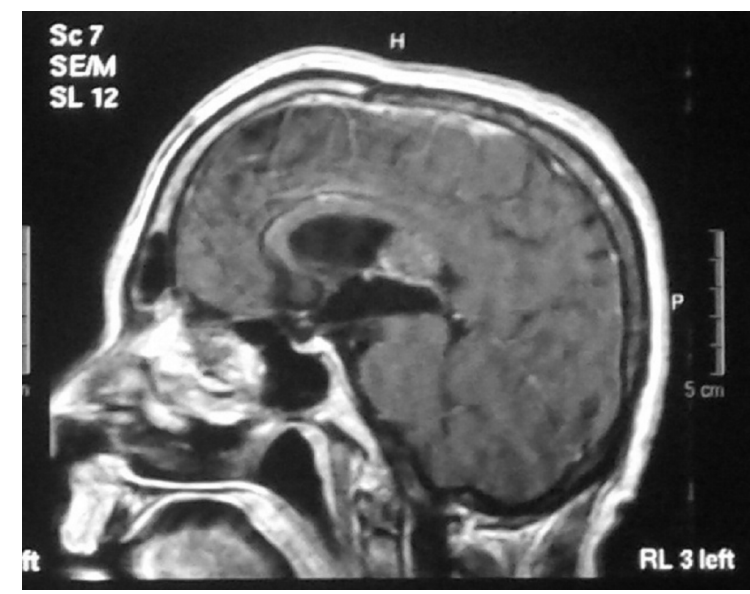

Figure 8. Lesion at the posterior third of septum pellucidum.

3) An inferior parietal transcortical approach.

The usually recommended procedure is option “1.”. Narisawa et al. [7] and also Katoh et al. [19] refer to the transcallosal approach for the excision of their patient's septal cavernomas. Another example is the article of Wang et al. [20] who presented a series of 41 patients with septal tumors which were operated via transcallosal, frontal transcortical and transulcal approaches only, concluding that transcallosal was the safest. For the centrally located relatively small tumor of our case it actually made neuroanatomical sense to proceed transcallosally.

Option “2.” while recommended for ventricular body lesions [21], is not widely used as the current reviews on the subject show. Anderson et al. [22] refer to this approach concerning their case of a giant cavernoma of the body (middle and posterior part) of the lateral ventricle. In the review of 49 cases of lateral ventricle cavernomas by Carrasco et al. [23] there was only one case of cavernoma of the ventricular body for which the followed approach unfortunately was not reported. In the same article a variety of our proposed approach, the parietal-temporal transventricular was used for tumors of the trigone only.

Option " 3. ." is usually recommended for lesions involving the trigone but not the body of the lateral ventricle. This is for example what Koos, Spetzler \& Lang recommend in their microsurgical atlas [24]. Also Rhoton [20] does not comment on the inferior parietal approach as a procedure of choice for lateral ventricle pathology surgical management. ${ }^{2}$ Our PubMed search did not return a single published case where a posterior third septum pellucidum or posterior body of the lateral ventricle pathology was operated on via this approach. Also while Seçer et al. [25] recommend a parietal transcortical approach for removal of tumors of both the atrium and the body of the lateral ventricle, their cortical entry point is at the superior parietal lobule, therefore they describe option " 2 " above.

Despite of the above we preferred the last approach based on the senior surgeon's (GG) previous experience but also keeping into consideration the following factors:

- The possible neurological séquelle of the transcallosal approach [26].

- The problematic operative trajectory angle to the posterior septum via the superior parietal lobule.

- The need to keep a safe anatomical distance from eloquent cortex.

- The need to have direct access to the intraventricular hemorrhage.

Finally a short description of positioning and surgical technique: The patient was placed in the lateral position with care so that the parietal plateau lied most superiorly in parallel with the ground (Figure 9). The small craniotomy was framed around Keen's point and the cortical incision did not exceed 1.5 to 2 cm in diameter. We believe that this is particularly important in cases where the lesion needs to be approached from the left where the angular gyrus lies closely anteriorly to Keen's point. A ventricular drainage catheter was placed as a guide to the occipital horn and atrium. The vein of Labbé was identified and protected with a pad. Other operative concerns included the quite long distance to the lesion and the deficient control of the contralateral site of the tumor. Care was taken, following microdissection around the lesion, to have visual control of the potentially exposed internal cerebral veins, their major tributaries and the ipsilateral body and/or crux of the fornix so that not to damage these vital structures. Care was also taken in order to avoid unnecessary injury to the optic radiation

${ }^{2}$ But we should note that Figures 5.3 K. and L. in Rhoton (2002: S1-213) picture in exact terms the operative trajectory of the inferior parietal approach we are referring to. 


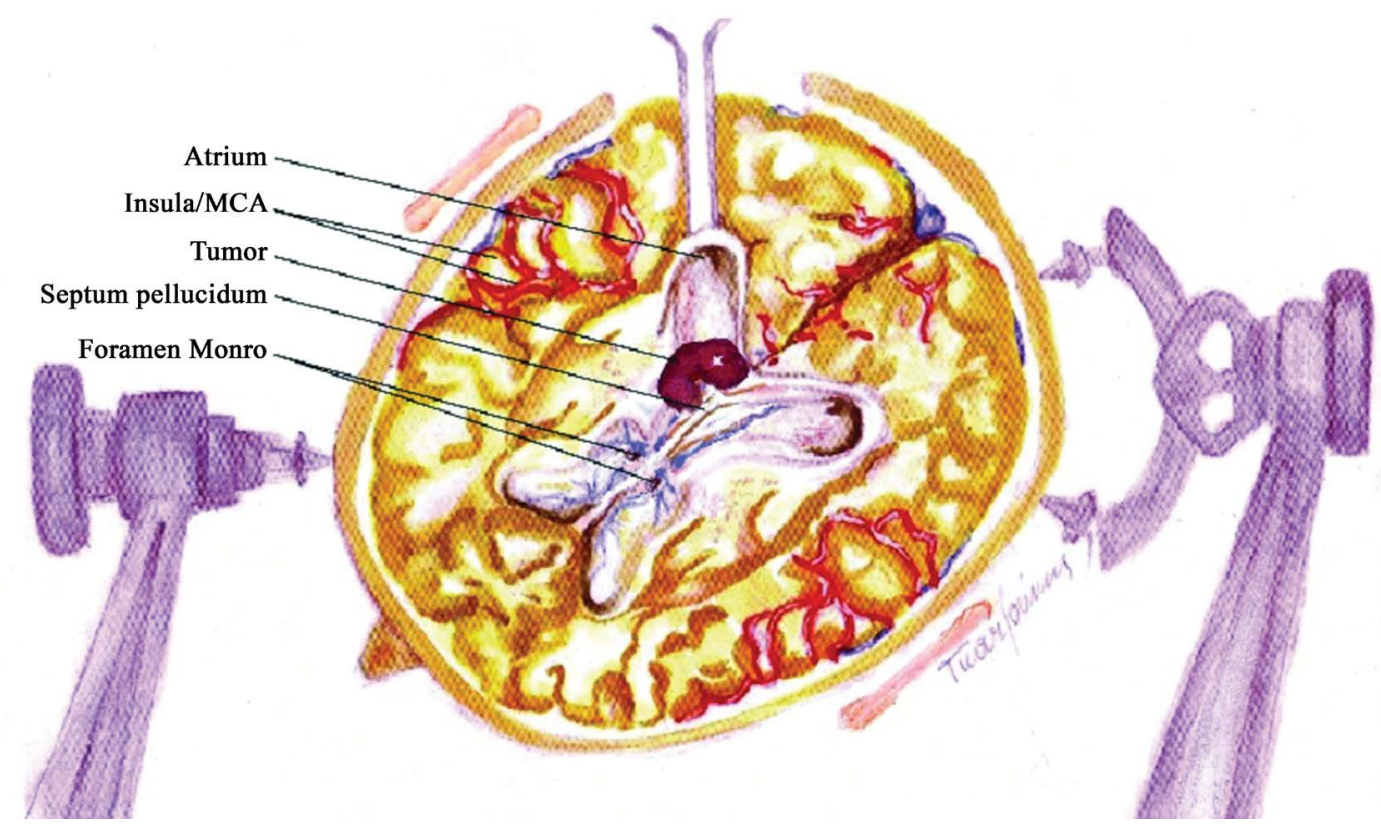

Figure 9. The parietal plateau should be situated on the top facing the surgeon. A vertical or a slightly oblique trajectory should be attempted so that the anatomical corridor of the occipital horn and atrium is respected.

with thoughtless retraction at the lateral and inferior sides of the atrium and occipital horn. The small cortical and white matter operative corridor ensured that a possible visual field lesion was kept to a minimum [27] [28].

\section{Conclusion}

Septum pellucidum cavernous angiomas are rare entities. There are only few cases reported to the literature at present. We present a case report of such a cavernous angioma, review the available cases published in the literature and shortly discuss the surgical options available in comparison, taking into account the challenges of the area. In our case, despite the commonly used procedures in the literature, inferior parietal approach was selected. We would recommend the use of this approach as a reasonably safe and effective alternative in selected cases.

\section{Acknowledgements}

We would like to thank Alexios Bimpis for his useful comments on the final draft of the paper.

\section{Conflict of Interest}

None.

\section{References}

[1] Greenberg, M.S. (2010) Handbook of Neurosurgery. 7th Edition, Kindle Edition, Thieme, New York, 48280-48281.

[2] Faropoulos, K., Panagiotopoulos, V., Partheni, M., Tzortzidis, F. and Konstantinou, D. (2015) Therapeutic Management of Intraventricular Cavernoma: Case Series and Review of the Literature. Journal of Neurological Surgery Part A: Central European Neurosurgery, 76, 233-239. http://dx.doi.org/10.1055/s-0034-1389093

[3] Lobato, R.D., Perez, C., Rivas, J.J. and Cordobes, F. (1988) Clinical, Radiological, and Pathological Spectrum of Angiographically Occult Intracranial Vascular Malformations. Analysis of 21 Cases and Review of the Literature. Journal of Neurosurgery, 68, 518-531. http://dx.doi.org/10.3171/jns.1988.68.4.0518

[4] Simard, J.M., Garcia-Bengochea, F., Ballinger Jr., W.E., Mickle, J.P. and Quisling, R.G. (1986) Cavernous Angioma: A Review of 126 Collected and 12 New Clinical Cases. Neurosurgery, 18, 162-172. http://dx.doi.org/10.1227/00006123-198602000-00008

[5] Voigt, K. and Yaşargil, M.G. (1976) Cerebral Cavernous Haemangiomas or Cavernomas. Incidence, Pathology, Localization, Diagnosis, Clinical Features and Treatment. Review of the Literature and Report of an Unusual Case. Neuro- 
chirurgia, 19, 59-68. http://dx.doi.org/10.1055/s-0028-1090391

[6] Muzumdar, D., Avinash, K. and Ramdasi, R. (2015) Cavernoma of the Septum Pellucidum in the Region of Foramen of Monro. Neurology India, 63, 68. http://dx.doi.org/10.4103/0028-3886.152641

[7] Narisawa, A., Kumabe, T., Anzai, T., Utsumi, Y. and Tominaga, T.A. (2007) Case of Cavernous Angioma at the Septum Pellucidum. No Shinkei Geka. Neurological Surgery, 35, 53-58.

[8] Kasliwal, M.K. and Sharma, B.S. (2011) Giant Intraventricular Mass Arising from the Septum Pellucidum. Cavernoma. Journal of Clinical Neuroscience: Official Journal of the Neurosurgical Society of Australasia, 18, 1108, 1145. http://dx.doi.org/10.1016/j.jocn.2010.03.049

[9] Monaco, E.A., Khan, A.A., Niranjan, A., et al. (2010) Stereotactic Radiosurgery for the Treatment of Symptomatic Brainstem Cavernous Malformations. Neurosurgical Focus, 29, E11. http://dx.doi.org/10.3171/2010.7.FOCUS10151

[10] Nagy, G., Razak, A., Rowe, J.G., et al. (2010) Stereotactic Radiosurgery for Deep-Seated Cavernous Malformations: A Move toward More Active, Early Intervention. Journal of Neurosurgery, 113, 691-699. http://dx.doi.org/10.3171/2010.3.JNS091156

[11] Katayama, Y., Tsubokawa, T., Maeda, T. and Yamamoto, T. (1994) Surgical Management of Cavernous Malformations of the third ventricle. Journal of Neurosurgery, 80, 64-72. http://dx.doi.org/10.3171/jns.1994.80.1.0064

[12] Tu, J., Stoodley, M. A., Morgan, M. K., Storer, K. P. and Smee, R. (2009) Different Responses of Cavernous Malformations and Arteriovenous Malformations to Radiosurgery. Journal of Clinical Neuroscience: Official Journal of the Neurosurgical Society of Australasia, 16, 945-949. http://dx.doi.org/10.1016/j.jocn.2008.09.017

[13] Ogawa, A., Katakura, R. and Yoshimoto, T. (1990) Third Ventricle Cavernous Angioma: Report of Two Cases. Surgical Neurology, 34, 414-420. http://dx.doi.org/10.1016/0090-3019(90)90246-L

[14] Shih, Y.-H. and Pan, D.H.-C. (2005) Management of Supratentorial Cavernous Malformations: Craniotomy versus Gamma Knife Radiosurgery. Clinical Neurology and Neurosurgery, 107, 108-112. http://dx.doi.org/10.1016/j.clineuro.2004.06.004

[15] Fratzoglou, M., Leite dos Santos, A.R., Gawish, I. and Perneczky, A. (2005) Endoscope-Assisted Microsurgery for Tumors of the Septum Pellucidum: Surgical Considerations and Benefits of the Method in the Treatment of Four Serial Cases. Neurosurgical Review, 28, 39-43.

[16] Prat, R. and Galeano, I. (2008) Endoscopic Resection of Cavernoma of Foramen of Monro in a Patient with Familial Multiple Cavernomatosis. Clinical Neurology and Neurosurgery, 110, 834-837. http://dx.doi.org/10.1016/j.clineuro.2008.05.011

[17] Gaab, M.R. and Schroeder, H.W. (1999) Neuroendoscopic Approach to Intraventricular Lesions. Neurosurgical Focus, 6, e5. http://dx.doi.org/10.3171/foc.1999.6.4.8

[18] D’Angelo, V.A., Galarza, M., Catapano, D., Monte, V., Bisceglia, M. and Carosi, I. (2005) Lateral Ventricle Tumors: Surgical Strategies According to Tumor Origin and Development. A Series of 72 Cases: Neurosurgery, 56, 36-45. http://dx.doi.org/10.1227/01.neu.0000144778.37256.ef

[19] Katoh, M., Sawamura, Y., Moriwaki, T., et al. (2013) A Case of Cavernous Angioma in the Septum Pellucidum. Clinical Neurology and Neurosurgery, 115, 1126-1127. http://dx.doi.org/10.1016/j.clineuro.2012.09.010

[20] Wang, L., Zhang, M., Zhang, W., Zhao, S., Zhao, J. and Jia, J. (2005) Clinical and Pathological Characteristics of Septum Pellucidum Tumor and Choice of Surgical Approaches for Its Resection. Chinese Medical Journal, 118, 812-816.

[21] Rhoton, A.L. (2002) The Supratentorial Cranial Space: Microsurgical Anatomy and Surgical Approaches. Neurosurgery, 51, No. 4.

[22] Anderson, R.C., Connolly Jr., E.S., et al. (2003) Clinicopathological Review: Giant Intraventricular Cavernous Malformation. Neurosurgery, 53, 374-378; Discussion 378-379. http://dx.doi.org/10.1227/01.NEU.0000073533.52727.E4

[23] Carrasco, R., Pedrosa, M., Pascual, J.M., Navas, M., Liberal, R. and Sola, R.G. (2009) Cavernous Angiomas of the Lateral Ventricles. Acta Neurochirurgica, 151, 149-154. http://dx.doi.org/10.1007/s00701-009-0186-8

[24] Koos, W.T., Spetzler, R.F. and Lang, J. (1993) Color Atlas of Microneurosurgery. 1. Intracranial Tumors. Thieme, New York.

[25] Seçer, H. I., Düz, B., Izci, Y., Tehli, O., Solmaz, I. and Gönül, E. (2008) Tumors of the Lateral Ventricle: The Factors That Affected the Preference of the Surgical Approach in 46 Patients. Turkish Neurosurgery, 18, 345-355.

[26] Hütter, B.O., Spetzger, U., Bertalanffy, H. and Gilsbach, J.M. (1997) Cognition and Quality of Life in Patients after Transcallosal Microsurgery for Midline Tumors. Journal of Neurosurgical Sciences, 41, 123-129.

[27] Nishizaki, T. (2012) Surgical Approaches for Lateral Ventricular Trigone Meningioma. In: Monleon, D., Ed., Meningiomas-Management and Surgery, InTech, Croatia. http://dx.doi.org/10.5772/30228

[28] Kawashima, M., Li, X., Rhoton, A.L., Ulm, A.J., Oka, H. and Fujii, K. (2006) Surgical Approaches to the Atrium of the Lateral Ventricle: Microsurgical Anatomy. Surgical Neurology, 65, 436-445.

http://dx.doi.org/10.1016/j.surneu.2005.09.033 